KURZ GEMELDET

Allergy News

\section{Fisch für Babys!}

— ine einzige Fischmahlzeit vor Erreichen des neunten Lebensmonats reduziert statistisch das Risiko, im ersten Lebensjahr an einem Ekzem zu erkranken, um 25\%. Dies fanden Epidemiologen der Universität Göteborg heraus, die die Langzeitdaten von über 17.000 Säuglingen auswerteten. Für die protektive Wirkung der Fischmahlzeit war es völlig unbedeutend, welche Art von Fisch (arm oder reich am Omega-3-Fettsäuren) gegessen wurde. de

Alm B et al. Arch Dis Child 2008 Sep 25 [Epub ahead of print]

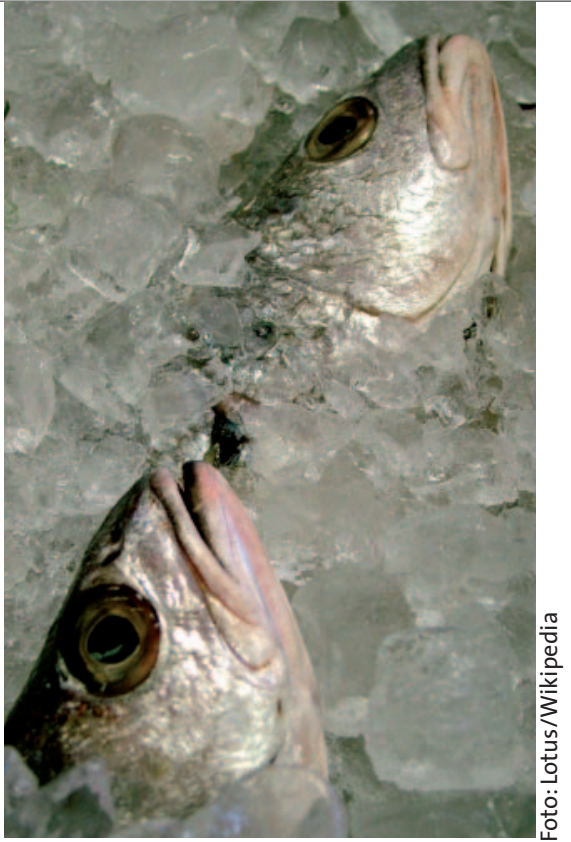

\title{
Atopischer Marsch in transplantierte Lunge
}

\begin{abstract}
A llergische Erkrankungen lassen sich nicht „wegoperieren“. Dies zeigt der Fall eines 13-Jährigen mit Asthma und Rhinokonjunktivitis aufgrund einer Sensibilisierung gegen Birken- und Gräserpollen, der wegen einer Kardiomyopathie und sekundärer pulmonaler Hypertension eine neue Lunge erhalten hatte. Der Spender war nicht atopisch. Nach der Transplantation waren die Asthmasymptome zunächst vollständig verschwunden, das Organ arbeitete sehr gut. Allerdings zeigte der Junge während der Pollenflugzeiten auch weiterhin Rhinokonjunktivitissymp-
\end{abstract}

tome mit einem Anstieg der Zahl der BlutEosinophilen - trotz Immunsuppression mit Tacrolimus und Prednisolon. Drei Jahre nach der Transplantation - in einem Jahr mit besonders starkem Gräserpollenflug - wurde der Patient dann mit Asthmasymptomen stationär aufgenommen. Unter einer Standardasthmabehandlung verschwanden die Symptome, im Metacholintest sechs Wochen nach dem Ereignis wurde eine bronchiale Hyperreagibilität festgestellt.

$b k$

Schwerk N et al. Allergy 2008; 63: 628-9

\section{latrogene Xanthodermie}

_ ine Xanthodermie muss nicht immer - hepatischen Ursprungs sein, sondern kann auch banale exogene Ursachen haben, so bei einer 46-Jährigen mit einer ausgeprägten, die Konjunktiven aussparenden Gelbverfärbung der Haut und normalen Bilirubin- und $\beta$-Karotin-Spiegeln. Bei einer systemischen Mastozytose litt die Patientin an einer gastralen Hyperazidität, die seit zwei Jahren mit dem Ranitidin-Präparat Zantac ${ }^{\circledR}$ behandelt wurde. Die Frau nahm viermal täglich je drei 300-mg-Tabletten ein - und damit auch den darin enthaltenen, leuchtend gelben Farbstoff D\&C Yellow No. 10. Nach Umstellung auf einen H2-Blocker ohne Farbstoff normalisierte sich das Hautkolorit innerhalb von zehn Monaten. $\quad b k$

Bruckner NV. J Am Acad Dermatol 2008; 58: 895-6

\section{Keimfreie Fläschchen}

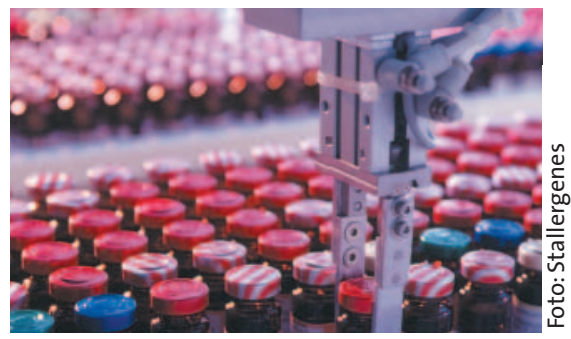

M illionenfach erhalten Patienten Jahr für Jahr im Rahmen einer spezifischen Immuntherapie (SIT) Allergeninjektionen. Berichte über Infektionen dadurch gibt es so gut wie keine - obwohl die Allergenlösungen Mehrfachdosenbehältern entnommen werden, die potenziell verkeimen können. Ein US-amerikanisches Ärzteteam wollte es genau wissen und veranlasste eine bakterielle Untersuchung von 136-SIT-Mehrfachfläschchen, die über einen Zeitraum von acht Monaten nach normaler Nutzung unter Beachtung der üblichen Hygieneregeln gesammelt worden waren. Das Ergebnis war eindeutig: Alle Behältnisse waren keimfrei.

Calderón PE et al. J Eur Acad Dermatol Venereol 2008; 22: 898-9
Lin SY et al. Otolaryngol Head Neck Surg 2008; 139: 195-7 